\title{
Factors Influencing Uptake of Exotic Dairy Goats in Kitui West Sub-County, Kitui County, Kenya
}

\author{
Bwanawoy Philemon ${ }^{1}$, Timothy Maitho ${ }^{2}$ \\ ${ }^{1}$ Department of Education and External Studies, University of Nairobi, Nairobi, Kenya \\ ${ }^{2}$ Department of Public Health, Pharmacology and Toxicology, University of Nairobi, Nairobi, Kenya
}

Email address:

philemon.bwanawoy@gmail.com (B. Philemon), tmaitho@uonbi.ac.ke (T. Maitho)

\section{To cite this article:}

Bwanawoy Philemon, Timothy Maitho. Factors Influencing Uptake of Exotic Dairy Goats in Kitui West Sub-County, Kitui County, Kenya. International Journal of Science, Technology and Society. Vol. 5, No. 5, 2017, pp. 153-166. doi: 10.11648/j.ijsts.20170505.13

Received: July 2, 2017; Accepted: July 20, 2017; Published: August 15, 2017

\begin{abstract}
This study investigated factors influencing uptake of exotic dairy goat farming in Kitui West Sub County, Kenya. Goat farming has gained popularity globally especially among small holder farmers and many countries are making tremendous efforts to support farmers improve their quality an productivity. Many smallholder farmers in Kenya have developed interest in exotic dairy goats farming and factors which enhance uptake were investigated. The study assessed and investigated socio-demographic, local community leadership, management practices and economic factors influencing uptake of dairy goats which should be addressed in the sub-County. The paper recommends interventions which can address impediments to uptake of dairy goats. The data was analyzed using descriptive statistics and was presented using percentages, frequencies, means and Tables. The findings showed that cultural background hindered respondents from effectively engaging in exotic dairy goats farming. From the Pearson moment correlation, there was a weak positive correlation between uptake of exotic dairy goats and social demographic factors with a correlation coefficient of 0.333 with a significant value of 0.001 ; which was less than 0.05 . A correlation coefficient of 0.911 at 0.0003 level of confidence indicated a strong positive correlation between the uptake of exotic dairy goats farming and local community. Also strongly positively correlated was the uptake of exotic dairy goats farming and farm management skills with a correlation coefficient of 0.872 at 0.002 level of confidence. There was strong negative correlation between uptake of exotic dairy goat farming and economic factors with a correlation coefficient of 0.044 at 0.000 level of confidence. It was concluded that socio-economic factors are significant in determining uptake of exotic dairy goats farming. The study findings are important because they will assist in improving goat breeding and improve farmers' income and livelihood. There is a need to strengthen awareness in order to change farmers' attitude and enhance uptake of exotic dairy goats farming.
\end{abstract}

Keywords: Factors Influencing, Uptake, Exotic Dairy Goats, Small Holder Farmers, Kitui West Sub-County

\section{Introduction}

Global rearing of exotic dairy goats has been on an upward trend in terms of stock and production [8]. The trend of goat production systems has been directly proportional to the decreasing size of farms which haven't been able to accommodate high number of goats. There has been a decrease in pastoral practices especially in the production of milk as their numbers increase.

According to [26, 39], rearing of goats has been the tradition in some European Countries like Italy, Greece and France where cheese and goat milk production takes lead.
The same trend has been experienced in the European nations like Austria and Germany. Goat population globally is estimated to be over 924 million with growth rate standing being 13 percent $[19,17]$.

Goats contribute significantly to economic stability and food supply within the rural smallholder set-up [17]. It was further reported that goats can contribute immensely to the economic issues and food supply among the rural smallholder farmers. However, the demand for the farmers' products has continued to exceed their availability.

Despite increased improvement in pastoral practices in milk production, stock of major milk producing breeds have significantly been on the rise [8]. Asia leads other 
continents globally in the rearing of goats, producing around 539 million (61.6 percent), with Africa coming second with over 276 million goats; which contributes 31.6 percent of the global livestock production. Goat population is highest in China globally with over 142 million heads with Pakistan being second with around 61.4 million goats, closely followed by Nigeria whose goat population is around 57.3 million heads. India leads in the production of goat's milk globally with 4594 metric tonnes, which translates to 28.98 percent of the global production ahead of Bangladesh at 2496 metric tonnes. In the African continent, Mali comparatively produces the highest amount of milk (703 metric tonnes) and accounts 4.3 percent of the global milk production [8]. In Other studies, [35] established that 26 percent of the small ruminant population comes from Africa and this constitutes 4.3 percent of the global milk production.

It has been proved through studies that goats adapt well in a diverse environment to serve as a socio-economic asset in a fragile environment. Nutritionally goat's milk has been found to be comparatively easily digestible with minimal allergy as compared to cow's milk. Studies by scholars have further revealed that goats are important assets used in ceremonies where feasting and payment of social dues is done [51]. Goats sector serves as a source of income for small holder farmers with dismal capacity to maintain large herd of cattle [13]. However, $[13,47]$ has reported that the former is true for vulnerable families in rural areas of Sub-Saharan Africa.

There is a concern among smallholder farmers in East Africa in adopting intensive exotic dairy goats based on cross breeding indigenous breeds with exotic breeds, with governments making inconsistent and fruitless endeavours to develop this new sector [57]. Goats form a fundamental part in livestock sector in Kenya where goat population is around 10.9 million across the agro ecological zones [1]. Goats are the most appropriate and popular stock among small holder peasant farmers since they are affordable as compared to cattle. They can do with little land as well as being prolific, feeding on a variety of forage. This has significantly made goats enterprise a more lucrative economic engagement among rural peasant farmers practicing mixed farming which is a common system of production in Kenya.

Despite of significant introduction of dairy goats in various parts of Kenya, most projects in the rural areas have not been sustained with realized benefits ending soon just after withdrawal or termination of donor funding or after realization of impacts. Farmer participation in the genetic improvement of indigenous goat breeds has been dismal due to centralization of previous breeding programmes. Such programmes have ignored the smallholders who would have benefited from such programmes thus culminating in delayed and poor adoption of new innovations. Continued increase in human population and land fragmentation in Kenya has compelled farmers to engage in dairy goat farming as compared to cattle grazed for milk and beef production [33]. The authors noted that improved breeds of dairy goats along with accompanying technologies are given preference in order to fast track improvement of small stock managed by smallholder farmers in order to improve their economic status and nutrition. However, dairy goats farming in Kenya is gaining incredible support from development organizations and policy both in private and public sectors for improved income and livelihoods.

World Vision supported 300 vulnerable households in Kitui West Sub County with exotic dairy goats to improve household food security and income through sale of surplus goat's milk and male off-springs. The beneficiaries comprised widows, those living with HIV and AIDS (PLWHA) and caregivers of orphaned and vulnerable children (OVC).

According to [36], the dairy goats kept by smallholder farmers in Kitui West Sub-County were sourced from a reputable government dairy goats breeding institution, Kitui West Dairy Goats Association (KWDGA) with each family (household) receiving one Toggenburg Doe and two Galla Does and a shared Toggenburg buck. In the project area, the most preferred and reared small stock by farmers is the indigenous breeds of goats at 42.2 percent (Benslyn Consultants, 2011).

Farmers were trained on all aspects of dairy goats' husbandry practices with farmer ToTs that was formed to complement extension services offered by the County government through the Ministry of Agriculture, Livestock and Fisheries development (Makodaih, 2013). According to Mutonguni Poverty Reduction Project (MPRP) evaluation report, (2011), exotic dairy goat farmers received training on dairy goats' husbandry as well as milk marketing and record keeping.

Besides being dependent on livestock and peasant farming to derive livelihood, most vulnerable families in Kitui West Sub-County still depend on food aid from the government, NGOs and other well-wishers during drought period to augment income from dairy goats farming.

\section{Literature Review}

\subsection{Up-Take of Exotic Dairy Goats}

According to [58], a process termed as the "InnovationDecision Process" may give rise to adoption or rejection of a conceived innovation. The same decision, if adopted can be reversed at a later stage. Many other factors can also contribute to the adoption process.

According to [2], the dairy goat industry has seen improvement and increased attention resulting from their benefits of poverty reduction. This has been attributed to the income generation from the sale of goats' milk, skin, manure for crop propagation and meat hence acting as a financial intermediary to the resource constraint farmers [15]. [1, 6] further points that engaging in this sector is not only beneficial in poverty alleviation through income generation but also in eradicating hunger through consumption of the 
animal protein and hence improved nutritional status of rural communities.

\subsubsection{Increased Household Income}

Improved small scale farmers' income in Babati and Kongwa districts in Tanzania was attributed to improved production of dairy goats [38]. Dairy goat farming has attracted more peasant farmers as an income earner as well as source of milk and meat for the family [60]. Improved goats have continued to serve as a key measure in addressing poor farmers' needs in the rural areas due to their affordable initial and maintenance costs.

\subsubsection{Enhanced Production and Management of Exotic Dairy Goats}

Programmes introduced exotic dairy goat breeds to smallholder farmers in rural areas with an aim to upgrade the indigenous breeds for improved growth rate and milk production. This would ultimately lead to an improvement in food security and household income [57]. Smallholder farmers' interest on dairy goats to wade off malnutrition and poverty improved; a strategy boosted by the government [49]. Many farmers find quality dairy goat forages on easily accessible communal lands since goats are browsers and prefer to eat trees and shrubs as opposed to grass. Most of these trees and shrubs are drought tolerant and have potential to improve dairy goat health and milk production, especially during dry spells [59].

\subsection{Socio-demographic Factors and Uptake of Exotic Dairy Goats}

Socio-demographic factors have been found to contribute to uptake of dairy goats farming irrespective of farmers' level of education, household or family size, gender roles and age of the household head. The livestock population standing in Kenya is 12.5 million cattle, 8 million sheep, 142,730 goats and 850,000 camels [29]. Compared to cattle milk, goat's milk is allergy free and much enjoyed by people with allergy to cow's milk.

\subsubsection{Age of Household Head}

Adoption and practice on new innovations have been traced more in farmers with more energy and active [43]. [62] argues in his land based enterprise study that technology adoption was not significantly influenced by young ranging from 25 to 40 years. Following [4] study, more experience is rooted to relatively older farmers who are more endowed with resources and authority that provide a stronger platform to try new innovations. From other studies, uptake of new ideas and age of the farmers are indirectly proportional where the aged are less receptive to innovations despite having the experience and resources [14]. Due to the inconsistency of findings between age and adoption, [45] concluded that the effect of age on adoption tended to be location and technology specific. Age can generate or erode confidence in new technology. [7] found age as inversely related to adoption of dairy technology.

\subsubsection{Gender Roles in Exotic Dairy Goats Farming}

Women perform relatively more roles and functions in rearing of shoats [40]. In Nigeria, women participate more in agricultural activities as compared to men and this is further confirmed whereby community projects addressing poverty and other socio economic impediments in Ghana and Nigeria have been successful due to women-led group work [28].

According to [55], rural areas of Malawi are dominated by farming of shoats by smallholder peasant farmers and women have proved to be more naturally enriched with scientific and practical knowledge of shoats' husbandry [40].

Performance of women in rural development has drawn praise from many quarters though perceived as dismal in some areas especially in the livestock industry. This has been linked to predominant and deep-seated cultural factors [28].

Patriarchal bias has partly contributed to gender-blindness; and this has been exacerbated by women's attitude as being associalised by their traditional taboos, thus significantly undervaluing the work women perform in the society [28]. In Bolivia women are tasked with livestock duties while men engage in crops farming but men's engagement is not much differentiated from household chores in surveys; neither are women functions and roles economically considered important for the country [12].

According to [28], both men and women may determine the use of resources but skewed in terms of level of satisfaction from the use of the same resource (s). According to $[10,28]$ men enjoy and override the de jure ownership rights regarding livestock and dominate decisions on property inheritance which is biased against women who have limited access to means of production relative to their labour contributions.

\subsubsection{Education Level of Dairy Goat Farmers}

The level of participation of farmers in the market is determined by their level of education [21]. For those who have the education, the number of years spend in an educational institution is also a major contributory factor as this directly affects the level of management and managerial competencies as well as the quality of implementing exotic dairy goat farming [44]. According to [37], successful and efficient dairy goat farming is dependent on education as this would spur production, processing and marketing practices. Farmers have higher chances and capability of adopting agricultural innovations and new marketing channels when they are exposed to more relevant knowledge. [65], confirms that education is key and significant when choosing modern milk marketing channels such as cooperative and private dairy plants. According to [4], a farmer is ready to buy in and make use of an innovation when he or she has a stable education background.

The relationship between farmers' education and attitude towards exotic dairy goat husbandry is an empirical question as it provides the dairy farmer with necessary skills to enhance adoption of exotic dairy husbandry practices. Exotic dairy goat husbandry practices involve technical applicability and a dairy farmer with high level of education is better 
placed to access and utilize information concerning a prospective innovation and ensure coherent evaluation of the associated risks is made when adopting the exotic practice which comprehends to the taught aspects [3].

The outcome of the taught improved husbandry practices to a dairy farmer is viewed on its adoption and putting them into practice. A farmer with more education has the ability to adjust to change as compared to a farmer with little or no formal education [9]. Such educated farmers are able to adjust and fit into new technologies and innovations under different prevailing conditions.

\subsubsection{Household Size}

Household size is directly proportional to labour availability in any set up. A bigger household would generate more labour and hence affects adoption of an enterprise like dairy goat farming that is accompanied by new technologies a resource poor farmer may not afford [30]. Higher production can be associated to availability more labour at household level [44]. It is further noted that a choice for a marketing channel is positively determined by the size of the household [53].

According to [20], resource poor farmers can mobilize and make gainful use of resources in groups where participatory decision-making is embraced by all. High According to dairy Goats Association of Kenya ([11], farmer groups registered with the association can easily access breeding stock or semen, buck rotation information, market for their milk and breeding goats through organized sales. They can also register their goats with Kenya Stud Book and Dairy recording service of Kenya. They can access extension services and be guided to develop breeding plans.

\subsection{Farm Management Practices and Uptake of Exotic Dairy Goats}

Kenya Agricultural Research Institute (KARI) has recognized the important role that dairy goats play and prioritized it as number three (3) in about fifty-nine (59) commodities and factor research programmes [66].

According to the Department for International Development [1, 20] and KARI carried out a research in central Kenya on community based goat productivity improvement. The results indicated that most of the breeding programmes initiated were done without involvement and input of the target beneficiaries. Low dairy goat technology uptake was suggested as an information gap in a research workshop in Machakos Kenya [66].

According to [63], goat feeding system and milk production are correlated. Intensive and semi intensive management systems assist smallholder dairy goat farmers to be self-sufficient by using home grown feed and labour [56]. However dairy goats reared in intensive or semi intensive systems produce more milk compared to those raised in free grazing systems since many farmers using the latter system of grazing hardly supplement their goat's diet.

Keeping records could help farmers see the cost and benefits of improving their management practices. Helping them to justify making changes in management, such as buying supplemental feed because they see it improves their milk production.

\subsubsection{Disease Control in Dairy Goats}

According to [25], livestock farmers have continued to use recommended feed supplements as well as disease management to cab the high costs that are associated with feeds and veterinary services. Some farmers haven't been able to afford the recommended dairy goat management practices. Some studies conducted have proven that cost of inputs such as feeds, labour, land, quality breeds, veterinary services have been quite impotent, accounting for 94 percent variation in total output.

\subsubsection{Experience of Goats Breeding}

Programmes involving crossbreeding temperate breeds with indigenous breeds of goats has been triggered by inferior programmes involved in stock replacement rand improvement in dairy goats for local breeds [33]. This has awakened programmes in the tropical countries to revert to local breeds as more such programmes emerge. This calls for dairy goat breeders and entrepreneurs to enhance stock quality with time.

Despite of the gains experienced in livestock breeding in developed countries significant prospects to initiate and promote the same in developing countries abound. Improved breeds can give rise in fast productivity improvement but this can only be achieved with environment appropriateness fitting within the production system that require limited resources and constraints [61].

To enable farmers achieve significant growth rates in weaning, their participation in breeding is crucial to maintain weights of weaned animals above $18 \mathrm{~kg}$ after attaining the age of 120 days. Goats form a fundamental part within livestock sector with an estimated goat population of 10.7 million across all the agro-ecological zones [24]. Goats are raised for their products such as milk, meat, hides and manure besides their convenience to feed [48]. The East African and the Galla goats are the two-main indigenous breeds in Kenya, kept mainly for meat production. According to [32], Dairy Goats Association of Kenya (DGAK) has strived to introduce artificial insemination service to improve genetic figure in dairy goats. 20 farmers were trained as community resource persons in central province of Kenya to assist offer services to all the regions in the province as well as parts of western province.

A well-balanced diet in goats feeding is a prerequisite for self-maintenance and production of milk. High quality fodder is a necessity since dairy goats are quite selective in feeding. Farmers may realize wastage if the feeds given are of low quality [29]. According to [19], breed is a key factor that can bring about reproduction performance variation. Improved genotype of dairy goats can enhance production of milk due to high heritability found for milk yields traits. It is worth noting that breeding programmes take time and a number of generations of goats to realize impact [52]. To establish milk production trend and status, buck's lineage, milk production 
of the buck's mother and sisters are essential [50].

\subsection{Economic Factors and Uptake of Exotic Dairy Goats}

Shoats have proven to be cost-effective and reliable enterprise in fragile environments of semi-arid areas as well as mountainous regions of the Sub-Saharan Africa where their products such as skins and hair provide [55]. Their products such as hair and skin provide treasured products besides milk and meat. Goats contribute up to $20 \%$ of the calories and $0.75 \%$ of meat in Kenya. It has been established that small ruminants' milk is rich in nutrients [47].

\subsubsection{Market Information}

According to [21], farmers participate effectively in the market when adequately and widely exposed and access market information. Good and clear marketing channels and well-structured market as well as consistent and timely flow of market information espouse farmer participation. This will trigger an increase in volume of sales and improved and stable income base. From the studies of milk marketing channels, the source of market information determines the sale of milk by farmers [5]. The information disseminated by the market trigger increased output sales of dairy goat farmers, making them more willing to participate actively in the marketing channels [54].

\subsubsection{Market Prices of Exotic Dairy Goats}

The cost of a quality dairy goat in Kenya is around ksh 10 , 000 to ksh 15,000 depending on the age and breed. However, prices for a near lactating Kenya Alpine dairy Doe goes up to ksh 20,000 [11]. According to [23], dairy goat farmers depend upon direct market sales for both milk and cheese. Other market outlets include the retailors as well as the internet sales which too offer the market outlets. Some individual farmers sell directly to local market markets within their localities while some sell a herd of stock to distant organized markets in big towns and cities.

\subsubsection{Volume of Goat's Milk Produced and Value Addition}

Consumers akin with products produced under safe environments have continued to promote local value chain development especially in Europe and United States. They attach such products with better quality and able to develop local markets.

According to [27], prospective local value chain of goat's milk has been identified and developed in the less developed countries. Detailed inquiry of workable smallholder innovations or initiatives in local value chain based on local resources and context have been established.

The selection of milk market networks was certainly influenced by the bulk of milk produced daily [64]. This is as a result of low production costs by the processors. Much milk is produced by farmers with access to improved veterinary services, whereas a small holder farmer may not afford [65]. Sokoine University of Agriculture (SUA) supported farmers endeavour in the promotion of goat's milk value chain and even initiating a milk collection centre in 2007 around Mgeta in Tanzania. This was as a result of a perception that milk supply was glut that called a collective effort to stimulate marketing and this was as a result of a feasibility study done by the University Researchers Agricultural and natural resource Transformation for Exotic Livestock $\mathrm{s}$ baseline survey programme [34].

\subsection{Theoretical Framework}

This study was based on the Diffusion of Innovations Theory which explains the "how, why, and at what rate" new innovations diffuse from one culture to another, relying on the human capital [58]. A number of social factors suffice and affect to an extent an adoption process. According to [58], communication channels through which an innovation diffused affects the level and rate of adoption. The same is determined by existing social system as well as the efforts of the change agents involved in the diffusion process. As studied, any such diffusion-decision process may determine either adoption or outright rebuff of an innovation despite of a possibility of reversal at some point in time [58].

Uptake or adoption of dairy goat farming is influenced by many factors, both institutional and farm-based. According to [58], a structure of a social system may also contribute to an individual's innovativeness as characterized by an adoption curve where adopters are classified; and in this regard an individual farmer may choose to adopt a technology or reject an innovation outright. Farmers may try the innovation, first as it befits their own situation before making a final decision to adopt it. It is further noted that such an indirect trial can expedite the innovation process. Rejection of an innovation may occur in any stage of an innovation -decision process.

\subsection{Conceptual Framework}

This imagined model that identifies the concepts under the study as well as their relationship [41]. It's a diagrammatic presentation showing the connection concerning the independent and dependent variables. It aims at explaining relationship between variables and it synthesizes the idea in a systematic way to provide direction. The conceptual framework is given in Figure 1. 


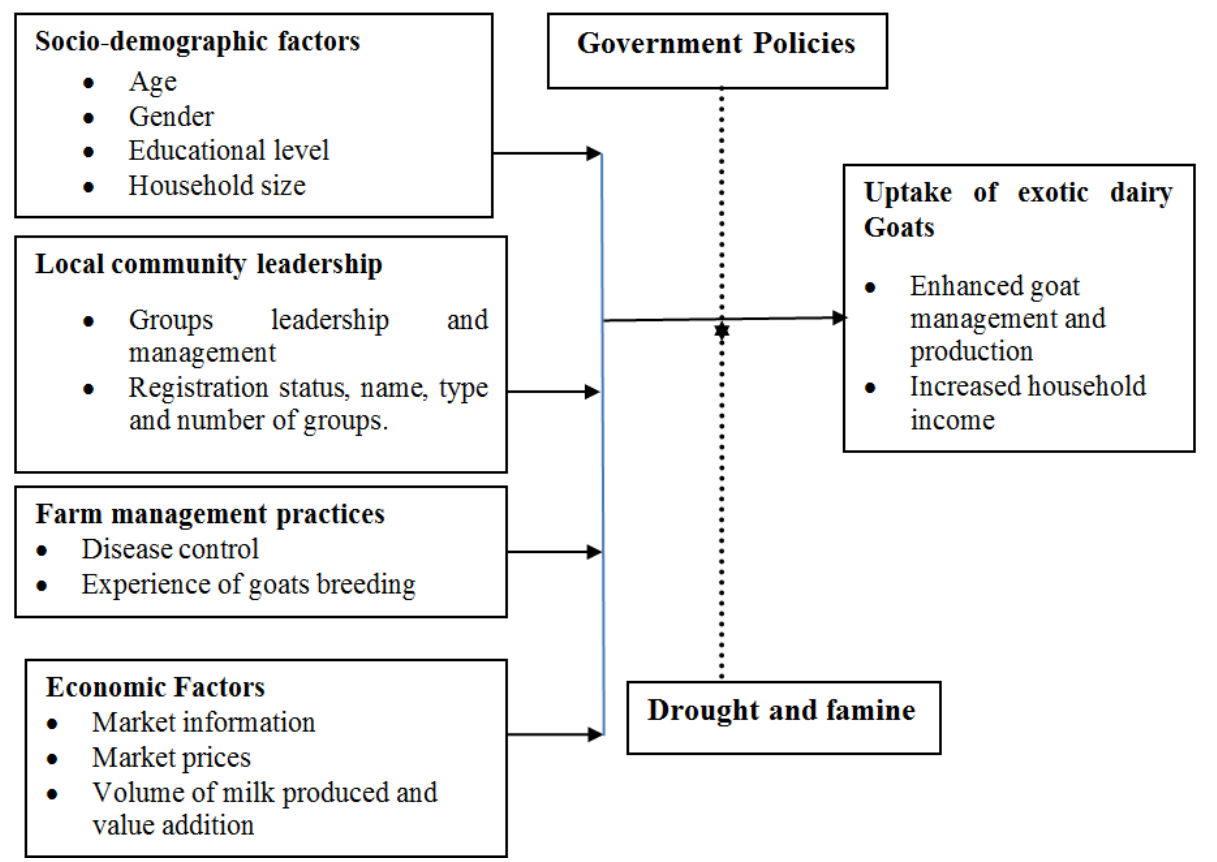

Figure 1. Conceptual Framework of the Study.

\section{Research Methodology}

The study used descriptive survey research design that assessed factors that influencing uptake of exotic dairy goats among smallholder farmers in Kitui West Sub-County. The survey research design used assisted the researcher to gather both qualitative and quantitative data on the study variables. The target population of the study comprised 300 smallholder farmers who kept exotic dairy goats and were selected randomly from the four locations of Kitui West Sub-County.

A sample of 178 was used in the study and included 168 dairy goat farmers and 10 Extension Officers. A desired sample size should be determined when a population exceeds 10,000 individuals [41]. Equal clusters were constituted out of the locations and a sample size was calculated using a recommended formula. [41] recommend use of the following formula.

$$
n f=\frac{n}{1+\frac{n}{N}}
$$

From the formula given above: -

$\mathrm{nf}=$ Desired sample size when the population is less than 10,000 .

$\mathrm{n}=$ Desired sample size when the population is more than 10,000 .

$\mathrm{N}=$ Estimate of the population size.

Applying the formula, the sample size for the exotic dairy goats was given as: -

$$
n f=\frac{384}{1+\frac{384}{300}}=168.4
$$

The adjusted sample size of 168 farmers was used during the distribution in the locations in order to collect heterogeneous data.

\subsection{Sampling Procedure}

Purposive sampling was used during the identification of key informants and focus group discussants of the study. This is a technique which allows a researcher to use cases that have the requisite information as guided by the objectives of the study. The subjects were hand-picked since they possessed the requisite characteristics as noted by [22].

In proportional sampling, each cluster or administrative unit was allocated a number according to the existing dairy goat farmers and each cluster was covered by one enumerator who interviewed 42 farmers.

A list of dairy goat farmers from each of the four clusters was provided to form a sample frame whereby enumerators picked one name of a farmer printed on a tag. This was done in turns in the respective clusters until all the names of the required respondents were picked in all the clusters. All the names picked by the enumerators constituted a survey sample of 168 exotic dairy goat farmers for the study.

\subsection{Methods of Data Collection}

Data was collected using questionnaire, Key Informant Interviews and observation. Questionnaire was used to acquire crucial information on the population. In this case, each item in the questionnaire addressed a respective research objective. Both open and closed ended questionnaire was subdivided into sections based on the objectives of the study. The questionnaire was administered to household heads of households keeping exotic dairy goats.

Pre-testing of the instruments was conducted to test their appropriateness and the document was reviewed based on the findings to remove any ambiguities noted during pre-testing. 
This was done from a different community with similar characteristics.

\subsection{Validity and Reliability of the Research Instruments}

The validity of the research instruments was established by conducting a pilot study that pre-tested the instruments which were used to give qualitative and quantitative data. The study utilized 10 percent of the sample size, which comprised 16 exotic dairy goat farmers that were selected randomly. According to [31], a pilot study allows for the identification of sources of errors; and defines validity as extent to which an instrument measures what it intends to measure. The validity of the instruments demonstrates the accuracy of the data obtained in the study with respect to the variables of the same study and gives the degree to which findings obtained from the analyses of the data represents the problem being investigated [41]

Reliability is where the research instruments give consistent research findings following several trials [41], and it is influenced by random error. [31] further argued that sources of errors in research can only be identified through a pre-test or a pilot study, involving subjects with the same characteristics but outside the study area. For this case, therefore pre-testing of the instrument was done before application.

The numerical scores were split into odd numbers and even number items; a process that got two sets of values that were correlated using Pearson product moment Correlation Coefficient.

$$
r=\frac{n \sum x y-\sum x \sum y}{\sqrt{\left\{n \sum \mathrm{x}^{2}-\left(\sum \mathrm{x}\right)^{2}\right\}\left\{n \sum y^{2}-\left(\sum y\right)^{2}\right\}}}
$$

The above correlation coefficient gave a value of 0.907 that is above 0.80 ; implying the degree of data reliability was high [41].

\subsection{Data Analysis Techniques}

Coding, entry and analysis of data was done using Statistical Packages for Social sciences. The analyzed data was presented in tables using percentages and frequencies. Qualitative data was analyzed systematically to obtain useful conclusions and inferences. A Pearson Moment Correlation was conducted to determine the strengths of their association.

\section{Results}

This section presents the data analysis, presentation and interpretation of the study findings. Other areas covered in the chapter include the background information of the respondents and the findings of the study following the objectives.

\subsection{Socio-demographic Factors}

This section discusses socio-demographic factors and their contribution towards uptake of exotic dairy goats.

\subsubsection{Distribution of Respondents by Age}

Various age groups were requested to indicate their age category. This was made in the understanding that different age sets hold various opinions relating to the subject of study. The results are presented in Table 1.

Table 1. Distribution of respondents by Age.

\begin{tabular}{lll}
\hline Age & Frequency & Percentage \\
\hline 20-29 Years & 44 & 28.2 \\
30-39 Years & 50 & 32.1 \\
40-49 Years & 49 & 31.4 \\
50 Years s and above & 13 & 8.3 \\
Total & 156 & 100.0 \\
\hline
\end{tabular}

Table 1 shows that, $32.1 \%$ of the respondents were spread between ages of 30 and 39 years while $31.4 \%$ of respondents fell between 40 and 49 years of age. $8.3 \%$ of the respondents were aged 50 years and above. This indicates that farmers of all age categories participated in the study and had some knowledge of rearing exotic dairy goats.

Respondents were requested to indicate their gender. This was made in order to ensure equity and fairness during involvement of farmers in gender study. The results are shown in Table 2

Table 2. Distribution of Respondents by gender.

\begin{tabular}{lll}
\hline Gender & Frequency & Percentage \\
\hline Female & 94 & 60.3 \\
Male & 62 & 39.7 \\
Total & 156 & 100.0 \\
\hline
\end{tabular}

The study results obtained showed that majority $(60.3 \%)$ of the farmers involved were females whereas $39.7 \%$ were males. This implies that exotic dairy goats farming in Kitui West Sub County is commonly dominated by female farmers.

\subsubsection{Level of Education}

The household heads were asked to give their level of education and this was sought to gauge their level of understanding on research subject and their easiness / comfortability in responding to research questions The household heads were asked to give their level of education and this was sought to gauge their level of understanding on research subject and their easiness / comfortability in responding to research questions. The findings were given in Table 3.

Table 3. Level of education.

\begin{tabular}{lll}
\hline Description & Frequency & Percentage \\
\hline Certificate & 95 & 60.9 \\
Diploma & 58 & 37.2 \\
Degree & 3 & 1.9 \\
Total & 156 & 100.0 \\
\hline
\end{tabular}

Results obtained show that majority $(60.9 \%)$ of farmers were holders of a certificate course. $37.2 \%$ of the respondents had diploma certificates, while $1.9 \%$ of them were degree graduates. This shows that majority of exotic dairy goat famers had requisite education and were able to comprehend the research questions posed and responded accordingly. 


\subsubsection{Household Size}

Farmers were requested to indicate their family size as this was perceived to influence their choice of engagement in dairy goats farming. The results are shown in Table 4.

Table 4. Household size.

\begin{tabular}{lll}
\hline Household Size & Frequency & Percentage \\
\hline Less than three & 45 & 28.8 \\
3 to 7 family members & 86 & 55.1 \\
8 to 10 family members & 25 & 16.0 \\
Total & 156 & 100.0 \\
\hline
\end{tabular}

Investigations on family size showed that $55.1 \%$ of the families involved had between 3 to 7 family members, $28.8 \%$ of the respondents indicated less than three while $16.0 \%$ of the respondents indicated 8 to 10 family members. This shows that majority $(55.1 \%)$ of exotic dairy goat famers came from familiars with between 3 and 7 family members.

\subsubsection{Effect of Cultural Background on Engagement in Dairy Goats Farming}

The study sought to determine whether cultural background hinder farmers from effectively engaging in dairy goats farming. The findings are given in Table 5.

Table 5. Effect of cultural background on engagement in dairy goats farming.

\begin{tabular}{lll}
\hline Opinion & Frequency & Percentage \\
\hline Yes & 117 & 75.0 \\
No & 39 & 25.0 \\
Total & 156 & 100.0 \\
\hline
\end{tabular}

From Table 5, majority (75.0\%) of respondents agreed that cultural background hindered them from effectively engaging in dairy goats farming, whereas $25.0 \%$ indicate otherwise. This implies that cultural background hindered farmers in Kitui west from effectively engaging in dairy goats farming. Respondents further repowered the common believe that exotic goats could not do well or survive in semi-arid areas delimited the adoption of exotic goats in Kitui West -Sub county

\subsection{Farm Management Practices}

The study examined a number of management practices exotic dairy goat farmers ought to uphold in order to realize improved goats productivity and household income.

\subsubsection{Control of External Parasites}

Farmers engaged were requested to indicate if they controlled external parasites. The findings are given in Table 6 .

Table 6. Control of external parasites.

\begin{tabular}{lll}
\hline Opinion & Frequency & Percentage \\
\hline Yes & 156 & 100 \\
Total & 156 & 100 \\
\hline
\end{tabular}

Results obtained from the analysis indicate that $100 \%$ of farmers controlled external parasites from attacking their goats.

\subsubsection{Spraying During Wet Seasons}

The study sought to establish the number of times exotic dairy goat farmers carried out spraying during the wet seasons as shown in Table 7.

Table 7. Spraying during Wet seasons.

\begin{tabular}{lll}
\hline Description & Frequency & Percentage \\
\hline Once/week & 21 & 16.7 \\
Once/two weeks & 34 & 27.0 \\
Once / month & 71 & 56.3 \\
Total & 126 & 100 \\
\hline
\end{tabular}

Results obtained from the analysis show that most $(56.3 \%)$ of the farmers carried out spraying exercise once in a month, $27.0 \%$ indicated that they carried out spraying exercise once /two weeks while $16.7 \%$ of the respondents indicated that carried out spraying exercise once/week. This implies that most of the farmers of exotic dairy goats in Kitui West Sub-County sprayed their goats once / month during the wet seasons. The study established the number of times farmers of exotic dairy goats carried out spraying during the dry seasons. The results are given in Table 8.

\subsubsection{Spraying During Dry Seasons}

The study sought to establish the number of times exotic dairy goat farmers sprayed their goats during dry season. The results are given in Table 8 .

Table 8. Spraying during the dry seasons.

\begin{tabular}{lll}
\hline Description & Frequency & Percentage \\
\hline Once/week & 23 & 18.3 \\
Once /two weeks & 90 & 71.4 \\
Once / month & 13 & 10.3 \\
Total & 126 & 100 \\
\hline
\end{tabular}

Results obtained from the analysis show that most (71.4\%) of the farmers carried out spraying exercise once /two weeks, $18.3 \%$ of the respondents carried out spraying exercise while $10.3 \%$ of the respondents carried out spraying exercise once/ month. This implies that most of the farmers of exotic dairy goats in Kitui sprayed their goats once /two weeks during the dry seasons.

\subsubsection{Dipping During Wet Seasons}

The study established how often dairy goat farmers in Kitui West Sub-County dipped their animals during wet seasons. The results are given in Table 9.

Table 9. Dipping during Wet seasons.

\begin{tabular}{lll}
\hline Description & Frequency & Percentage \\
\hline Once /two weeks & 1 & 3.3 \\
Once / month & 29 & 96.7 \\
Total & 30 & 100 \\
\hline
\end{tabular}

Results obtained from the analysis show that most (96.7\%) farmers carried out dipping exercise once in every month while $3.3 \%$ only carryout dipping once in every two weeks. This implies that majority of the dairy goat in Kitui West Sub-County dipped their goats once in a month during wet 
seasons.

\subsubsection{Dipping of Goats During Dry Seasons}

The study sought to establish the number of times farmers dipped their goats during dry seasons. The results are shown in Table 10.

Table 10. Dipping during the dry seasons.

\begin{tabular}{lll}
\hline Description & Frequency & Percentage \\
\hline Once/two weeks & 30 & 100 \\
Total & 30 & 100 \\
\hline
\end{tabular}

Results obtained from the analysis show that all farmers $(100 \%)$ carried out dipping exercise once after two weeks; implying that most of them carried out dipping during dry season only once in two weeks.

The study sought to determine whether the exotic dairy goats in Kitui west had access to veterinarian or other dairy goat health advisors. The results are given in Table 11.

Table 11. Access to a Veterinarian.

\begin{tabular}{lll}
\hline Opinion & Frequency & Percentage \\
\hline Yes & 100 & 64.1 \\
No & 56 & 35.9 \\
Total & 156 & 100.0 \\
\hline
\end{tabular}

Results obtained from the analysis show that majority (64.1\%) of the farmers had immediate access to veterinary services whereas $35.9 \%$ indicated to have access to veterinary services. This implies that considerable number of exotic dairy goats in Kitui west have no immediate access to Veterinary services.

\subsubsection{Type of Veterinary Services Available to the Dairy Goat Farmers}

The study sought to precisely establish whether the farmers had access to veterinary services or Health Advisors. The results are given in Table 12 .

Table 12. Types of Veterinary services available to farmers.

\begin{tabular}{lll}
\hline Services & Frequency & Percentage \\
\hline Veterinary & 74 & 74 \\
Health Advisors & 26 & 23 \\
Total & 100 & 100 \\
\hline
\end{tabular}

It is clear from the study that, $74 \%$ of the respondents indicated having access to veterinary services while $23 \%$ of the respondents indicated to have access to health advisor's services. This implies that only small percentage of the farmers who had access to veterinary services or health advisor's services.

\subsubsection{Control of Internal Parasites}

The research sought to establish whether farmers in Kitui west Sub County controlled internal parasites affecting their livestock. The findings are indicated in Table 13.
Table 13. Control of internal parasites.

\begin{tabular}{lll}
\hline Opinion & Frequency & Percentage \\
\hline Yes & 156 & 100.0 \\
Total & 156 & 100.0 \\
\hline
\end{tabular}

From the study findings, all the respondents indicated they controlled internal parasites affecting their livestock, this implies that of the considerable number of dairy goat's farmers in Kitui west Sub -County controlled internal parasites affecting their livestock.

\subsection{Economic Factors}

The study investigated the amount of milk received from goats per lactation and the findings are given in Table 14.

Table 14. Quantity of milk in litres received per goat per lactation.

\begin{tabular}{lll}
\hline Description & Frequency & Percentage \\
\hline $5-10$ litres & 103 & 66.0 \\
$15-20$ litres & 53 & 34.0 \\
Total & 156 & 100.0 \\
\hline
\end{tabular}

The research findings show that $66.0 \%$ of the respondents indicated that they received between 5-10 litres, 34.0 while $34.0 \%$ of the farmers shared that they got between 15 and 20 litres. This implies that most of the farmers received between 5 and 10 litres per goat per lactation.

\subsection{Source of Market Information for the Farmers}

Respondents were requested to indicate how they accessed market information. The results are given in Table 15 .

Table 15. Source of market information for the farmers.

\begin{tabular}{ll}
\hline Description & Percentage \\
\hline Radio & 71.8 \\
Extension agents & 73.7 \\
Fellow farmers & 74.4 \\
Local leaders & 66.0 \\
Total & 100 \\
\hline
\end{tabular}

The findings show that $74.4 \%$ of exotic dairy goat farmers received market information from fellow farmers, $73.7 \%$ of them relied on extension agents for market information, and $71.8 \%$ relied on radio for market information, whereas $66.0 \%$ relied on local leaders for market information. This implies that most of the farmers relied on radio, extension agents, fellow farmers, and local leaders as sources of market information.

\subsection{Correlation Coefficient}

The study conducted Pearson correlation analysis to indicate a linear association between the predicted and explanatory variables or among the latter, It, thus, helped in determining the strengths of association in the model (Table 16). 
Table 16. Correlation Results.

\begin{tabular}{|c|c|c|c|c|c|c|}
\hline & & $\begin{array}{l}\text { Adoption of exotic } \\
\text { Dairy goat farming }\end{array}$ & $\begin{array}{l}\text { Social demographic } \\
\text { factors }\end{array}$ & $\begin{array}{l}\text { Local community } \\
\text { leadership }\end{array}$ & $\begin{array}{l}\text { Farm management } \\
\text { skills }\end{array}$ & $\begin{array}{l}\text { Economic } \\
\text { factors }\end{array}$ \\
\hline $\begin{array}{l}\text { Adoption of exotic } \\
\text { dairy goat farming }\end{array}$ & $\begin{array}{l}\text { Correlation Coefficient } \\
\text { Sig. (1-tailed) }\end{array}$ & 1.000 & & & & \\
\hline $\begin{array}{l}\text { Social demographic } \\
\text { factors }\end{array}$ & $\begin{array}{l}\text { Correlation Coefficient } \\
\text { Sig. (1-tailed) }\end{array}$ & $\begin{array}{l}0.333 \\
0.001\end{array}$ & 1.000 & & & \\
\hline $\begin{array}{l}\text { Local community } \\
\text { leadership }\end{array}$ & $\begin{array}{l}\text { Correlation Coefficient } \\
\text { Sig. (1-tailed) }\end{array}$ & $\begin{array}{l}0.911 \\
0.003\end{array}$ & $\begin{array}{l}0.112 \\
0.001\end{array}$ & 1.000 & & \\
\hline $\begin{array}{l}\text { Farm management } \\
\text { skills }\end{array}$ & $\begin{array}{l}\text { Correlation Coefficient } \\
\text { Sig. (1-tailed) }\end{array}$ & $\begin{array}{l}0.872 \\
0.002\end{array}$ & $\begin{array}{l}0.027 \\
0.000\end{array}$ & $\begin{array}{l}0.046 \\
0.001\end{array}$ & 1.000 & \\
\hline Economic factors & $\begin{array}{l}\text { Correlation Coefficient } \\
\text { Sig. (1-tailed) }\end{array}$ & $\begin{array}{l}0.044 \\
0.000\end{array}$ & $\begin{array}{l}0.001 \\
0.003\end{array}$ & $\begin{array}{l}0.008 \\
0.001\end{array}$ & $\begin{array}{l}0.124 \\
0.000\end{array}$ & 1.000 \\
\hline
\end{tabular}

There was a week positive correlation between adoption or uptake of exotic dairy goats farming and socio-demographic factors with a correlation coefficient of 0.333 . This relationship is statistically significant with a value of 0.001 that is exceeded by 0.05 . With regard to this association, socio-demographic factors had some significance in the uptake of the dairy goats though with some households.

There was a strong positive correlation between adoption or uptake of exotic dairy goats farming by farmers and the local community leadership with a correlation coefficient of 0.911 at 0.003 level of confidence or statistical significance below 0.05. Local leaders and group management is paramount to the uptake and good management of the improved dairy goats in Kitui West Sub-County. In some instances leaders are relied upon for information relating management of dairy goats

The study also established a strong positive correlation between adoption or uptake of exotic dairy goat farming and farm management skills with a correlation coefficient of 0.872 at 0.002 level of confidence or statistical significance. Therefore for this case farmers with limited dairy goat husbandry skills may not be able to gain optimum gains from exotic dairy goat enterprise since poor management would lead to low productivity and inadequate income to sustain household socio-economic needs. Farmers with adequate formal education have a higher ability to adopt and practice new innovations for economic gain.

There was a strong negative correlation between the adoption or uptake of exotic dairy goats farming and economic factors with a correlation coefficient of 0.04 at 0.000 level of confidence. With weak financial capacity, farmers may not be able to offer quality management of dairy goats and this may result in poor performance and yields.

\section{Discussion}

Socio-demographic factors, farmers' level of farm management and economic factors have been found to influence the uptake of exotic dairy goats among rural farmers in Kitui West Sub County. The study further noted that most women in Kitui West Sub County were occupied by other household chores which could not allow them to attend training on dairy goats farming which delimited the adoption of the enterprise.
Older farmers were reluctant and unwilling to change farm management practices as compared to younger educated farmers. Those who have received more education on dairy goats tend to be more willing to adopt new technologies and join dairy farming practices. The findings are in line with the research by [65] who indicated that farmer's extensive grassland farms are more likely to participate in schemes than intensive livestock and arable farms.

Households with higher education had the likelihood of increasing the dairy product consumption. Males were likely to control resources in the households and influence farming decisions-making due to the view that they have more access to information, extension and credit services than females.

Regular dipping of dairy goats diseases is a sure measure of disease control. Most farmers practiced this once in a month during wet season and twice in a month during dry season. Considerable number of exotic dairy goats in Kitui west Sub-County had no immediate access to veterinary services, safe for a small percentage of farmers with access to veterinary services or health advisor's services. Considerable number of dairy goat's farmers in Kitui west Sub County controlled internal parasites affecting their livestock.

Farmers relied on radio, extension agents, fellow farmers, and local leaders as sources of market information. Apart from dairy farming farmers relied on crop farming, business and casual labour as alternative source (s) of income. Crop farming presented the highest source of income to most of the farmers and that majority of the farmers milked their does for a period of 4 months after kidding. These findings are in agreement with [46] report which notes that goats' milk begins to level after two months milking and up to 4 months in lactation.

\section{Conclusion}

It was concluded that socio-demographic factors influenced the uptake of dairy goats farming in Kitui West Sub-County. Cultural myths which surround the improved dairy goats in the region have been found to be some of the setbacks in the adoption or uptake of exotic dairy farming in Kitui West Sub-County.

Age factor has been found to play a key role in terms of acceptability and application of sound management practices when handling dairy goat enterprise with the old being slow 
to adopt improved breeds of goats. This exacerbated the uptake since most development organizations, both public and private in Kitui West Sub-County targeted the most vulnerable who comprises the old or the aged where many resources were invested on them but with very minimal impact in terms of transformational development.

Older farmers in Kitui west Sub County were less willing to change farm management practices, to young and middle level farmers who have acquired education and adequate agricultural extension services.

Local community leadership was shown to influence the uptake of dairy goats farming in Kitui West Sub-County. Local leadership influenced farmers' attitudes, perceptions, and behaviour. Effective leadership stimulates commitment and attracted membership on community development groups. Strong local community leadership was important in linking farmers to social economic stimulants, overseeing smooth implementation of every social economic development that promote the welfare of community members in general.

Farmers' management practices also influenced the uptake of dairy goats farming in Kitui west Sub-County. Inadequate knowledge and skills in record keeping, lack of modern farming skills especially in dairy farming delimited uptake of dairy goats farming in Kitui West Sub-County. The study also concluded that lack of access to livestock extension services negatively influenced the adoption of dairy goats farming in Kitui West Sub-County.

Economic factors were also shown to influence the uptake of exotic dairy goats farming in Kitui West Sub County. Market outlet, lack of funds, inadequate milk for marketing and inadequate land for grazing, have had negative influence on farmers' decision to adopt dairy goats farming in Kitui West Sub-County. Strong civilization on negative attitudes and believes towards dairy farming is important as this will significantly encourage farmers and promote uptake of the dairy enterprise in the area.

From the Pearson moment correlation, there was a weak positive correlation between the uptake of dairy goats farming and socio-demographic factors with a correlation coefficient of 0.333 . This strong relationship is statistically significant with a value of 0.001 that is exceeded by 0.05 . Therefore, socio-cultural factors play a fairly significant role in influencing the uptake of the livestock enterprise in the area as is the case with managerial skills among the dairy goat farmers who may require more training.

This study contributes significantly to the solutions on the problems of adoption of exotic dairy goat farming among smallholder farmers in Kitui West Sub-County. The findings of the study are useful in planning for enhanced milk production and household income and thus improve the standard of living among the smallholder farmer households. The study concluded that economic factors influenced the uptake of dairy goats farming in Kitui West Sub-County. However, market outlet, lack of funds, lack of sufficient market for milk and inadequate land for grazing, had a negative influence on farmers' decision to adopt dairy goats farming in the sub-
County. The study suggested that all the NGOs pushing the change need to enhance measures that promote awareness on the relevance of the improved dairy goats farming.

\section{Recommendations}

(1) The study suggests that all the NGOs pushing for the change need to enhance measures that promote awareness on relevance of dairy goats farming in order to promote the adoption of dairy goat farming in Kitui County.

(2) The study advocates for strong community leadership policies. Strong leadership will create a smooth path for implementation of change initiatives that endeavour to uplift the social economic welfare of the community.

(3) The study also advocates for comprehensive training on dairy goat farming practices as most farmers were found to be non-conversant with the internal goat farming practices. Training on record keeping and agribusiness management skills is an important primary measure towards adoption of dairy goats

(4) The County Government should work closely with community groups in order to foster a relation that promotes motivation and encourage participation in social economic activities. Such measures may include setting up of business incubators, sources of markets for farm produce, and favourable trade policies.

(5) There is a need to address socio-cultural myths by the community concerning exotic dairy goats in order to encourage them to improve their uptake for improved income and livelihoods.

(6) The Ministry of Agriculture, Livestock and Fisheries Development should deploy more Agricultural extension officers in the Kitui West Sub-County as there are few officers are faced with heavy workload with demotivated farmers on adoption of dairy livestock farming practice.

(7) Organizational capacity assessment of dairy goat farmer groups should be conducted in order to establish capacity gaps and train them.

(8) County government should work closely with community groups in order to foster a relation that promotes motivation and courage towards the laid social economic activities.

\section{References}

[1] Ahuya C. O., Okeyo A. M and Murithi F. M. (2003). Productivity of cross-bred goats under smallholder production systems in the Eastern highlands of Kenya. Research funded by International Development (DFID) for the benefit of developing countries.

[2] Ahuya C. O., Okeyo, A. M., Mwangi D. M and Peacock C. (2004). Developmental challenges and opportunities in the goat industry. The Kenyan experience. Paper presented at the th International Conference on Goats, July 4-9th, 2004, University of Pretoria. South Africa. 
[3] Akinbile L. A. (2003). Farmers Perception of Effectiveness of Fisheries Extension Services in Nigeria. Journal of Extension Systems 19 (1). 32-34.

[4] Amir K. K. G and Pannel, D. J. (1999). Conceptual Framework of adoption of agricultural innovation. Agricultural Economics Journal 21. 145-154.

[5] Awudu A. and Ramcke L. (2009). The Impact of Trade and Economic Growth on the Environment. Revisiting the CrossCountry Evidence. Kiel Institute for the World Economy, Düsternbrooker Weg 120, 24105 Kiel, Germany.

[6] Braker, M. J. E., Udo, H. M. J. and Webb, E. C., (2002). Impact of intervention objectives in goat production within subsistence farming systems in South Africa. S. Afr. J. Anim. Sci. 32, 185-191.

[7] Bulale A. I. (2000). Smallholder Dairy Production and Technology Adoption in the Mixed Farming System in Arsi Highland, Ethiopia. PhD Dissertation, Humbordt, University of Berlin. Germany.

[8] Chetroju R., Calin I. and Niculescu G. C. (2013). Worldwide trends and orientations of raising goats. MPRA Paper No.53460, posted 8-2-2014. 14 UTC.

[9] Crook, T. R., Tood, S. Y., Combs, J. G., Woehr, D. J. and Ketchen, D. J. (2011). Does human capital? A meta-analysis of the relationship between human capital and firm performance. Journal of AppliedPsychology 96 (3): 443 456.

[10] Dahl, E. and Malmberg-Heimonen, I. (2010). Social Inequality and Health. The role of social capital. Sociology of Health and Illness, 32.1102-1119. doi.10.1111/j.14679566.2010.01270. $x$.

[11] Dairy Goat Association of Kenya (2001, march). A service provider and farmers 'organization for poverty alleviation. Paper presented at annual general meeting of DGAK.

[12] De Schulze, M. V and Sostress M. F. (2000). Integration of women in development. North Chuquisaca Agricultural Development Project. Bolivia. USAID, Washington D. C., U.S.A.

[13] Degen T., Dillmann C., Marion P. F and Turnings T. C. (2004). High genetic variability of herbivore-induced volatile emission within a broad range of maize inbred lines. Plant Physiology 135, 1928-1938.

[14] Dogbe, E. (2006). Extension and Extension Agents, the way forward. Agricultural Economic Journal 31. 56-67.

[15] Dossa L. H., Sangaré M., Buerkert A and Schle E. (2008). Production objectives and breeding practices of urban goat and sheep keepers in West Africa, Regional analysis and implications for the development of supportive breeding programs. Andreas.

[16] Dubeuf J. P., Morand-Fehr P and Rubino, R., (2004). Situation, changes and future of goat industry around the world. Small Rumin. Res. 51,165-173. Paris.

[17] Ehim, S. K., Ahmed, M. M., Berhanu G., Benin, S. E., NinPratt, A. and Lapar Ma, L. (2003). 10 years of livestock policy analysis. Policies for improving productivity, competitiveness and sustainable livelihood of smallholder producers. ILRI, Nairobi, Kenya.
[18] Eik L. O., G. C., Kifaro S. M. Kiango O. M. Nordhagen J., Safari and L. A. Mtenga. (2008). Productivity of goats and their contribution to household food security in high potential areas of East Africa. A case of Mgeta, Tanzania. African J. Food, AgricNutrDevelop.

[19] FAOSTAT. 2012.

http://faostat.fao.org/site/569/DesktopDefault.aspx? PageID0569\#ancor Accessed 12/04/12

[20] FARM Africa, 2003. Delivering affordable and quality animal health services to Kenya's rural poor. FARM-Africa's experiences. FARM-Africa $\mathrm{Pb}$, ed. Feldman J. (2000). Minimization of Boolean complexity in human concept learning. Department of Psychology, Center for Cognitive Science. Rutgers University, New Brunswick, New Jersey, 08903, USA.

[21] Fuller J., Frank. H., Beghin, C. and Scott, R. (2004). Urban Demand for Dairy Products in China, Evidence from New Survey Data. Centre for Agricultural and Rural Development. Lowa State University. Working paper 4,380. Available on.

[22] Gay L., Mills G and Airasian P. (2006). Educational research competencies for analysis and applications. 8th ed. New Jersey, Pearson.

[23] Geisler M. (2015). Dairy Goats. A national information resource for value-added agriculture. AgMRC, Iowa State University. Iowa, USA.

[24] Government of Kenya (GOK) (2002). Ministry of Livestock. Annual report, Government printer press, Nairobi.

[25] Grimaud P., Mpairwe. D. Chalimbaud J., Messad S and Faye B. (2007). The place of Sanga cattle in dairy production in Uganda. Trop. Anim. Health Prod. 39.217.227.

[26] Grüner Bericht (2012). BMLFUW. www.gruenerbericht.at (accessed on 5-12-2012).

[27] Herr M. L. (2007). An operational guide to Local Value Chain Development. Combining Local Economic Development (LED) with Value Chain Development (VCD) to strengthen competitiveness and integration of SMEs into markets http.//www2.econ.iastate.edu/research/webpapers/paper 1222 1.pdf

[28] IFAD (2007). Rural Poverty Portal. Women livestock managers in the Third World. A focus on technical. Retrieved on 10-3-2010, from, http.//www.ifad.org/gender/

[29] Kamau P. and Baumgartner, P. (2011). The organic farmer. The Magazine for Sustainable Agriculture in Kenya, pp. 3.

[30] Kassie, M. and Holden, S. T. (2008). Sharecropping Efficiency in Ethiopia, Threats of Eviction and Kinship, Agricultural Economics, 37, 179-88.

[31] Kimberlin, C. L., and Winterstein, A. G. (2008). Validity and reliability of measurement instruments used in research. American Journal of Health System Pharmacists, 65 (23), 2276-2284.

[32] Kinyanjui, A., Murage A., and Mbugua, D. (2006). SocioEconomic Effects of Dairy Goat Production in Kenya. 10-102011, http.//www.kari.org//fileadmin/publications/.

[33] Kosgey I S, Baker R L, Udo H M J, and van Arendonk J A M 2006 Successes and failures of small ruminant breeding programmes in the tropics: a review. Small Ruminant Research 61: 13-28. 
[34] Krogh, E. (2007). Dairy Goats in Mgeta - Improvements of Livelihood. Proceedings of the Second Annual PANTIL Research Workshop. PANTIL SUA, Morogoro, Tanzania.

[35] Lebbie, H. B. (2004). Goats under household conditions. Small Ruminant Research. 51 (2), 131-36.

[36] Makodiah J. A. (2013). The role played by mobile phone communication in diffusion of dairy Goats rearing in Mutonguni Division, Kitui County. Kenya. Research paper, College of Agriculture and Veterinary Sciences (CAVS) [2226]. Nairobi, Kenya.

[37] Marenya, P., and Barrett, C. B. (2006). Household-level Determinants of Adoption of Improved Natural Resources Management Practices among Smallholder Farmers in Western Kenya. Food Policy, 32. 515-536.

[38] Mary J. (2012). Production performance and contribution of dairy goats to income of small scale farmers. A case of Babati and Kongwa districts in Tanzania.

[39] Morand-Fehr, P., Fedele, V., Decandia, M., and Le Frileux, Y. (2007). Influence of farming and feeding systems on composition and quality of goat and sheep milk. In Small Ruminant Research 68, 20-34. Elsevier.

[40] Moses, J. (2006). Goats and sheep: Production and marketing in the AMHARA region of Ethiopia. Final report draft. Assignment number AMAREW 06/2006. Retrieved March 10 2010

fromhttp://www.aasrp.org/Amhara\%20region\%20edition3.pdf

[41] Mugenda, O. M and Mugenda, A. G (2003). Research Methods Quantitative and qualitative approaches. Acts Press, Nairobi.

[42] Mwaura, F. (2014). Effect of Farmer Group Membership on Agricultural Technology Adoption and Crop Productivity in Uganda. African Crop Science Journal, Vol. 22, Issue Supplement s4, pp. 917-927.

[43] Nanai, N. A. K. (1993). Peasant Participation in Community Development Projects. Its Implication in Laying a Strategy for Participatory Extension. MSc. Thesis. Sokoine University of Agriculture, Morogoro, Tanzania.

[44] Ndinomupya M. A. (2010). Determinants of sustainable coffee marketing channel choice and supply response among organic and UTZ certified smallholder farmers. Evidence from Uganda. MSc Thesis submitted to Michigan State University.

[45] Nkonya, E. S. T. and Norman, D. (2003). Factors affecting adoption of improved maize seeds and fertilizers in Northern Tanzania. Agriculture Economics Journal. 48 (1). 136-145.

[46] Nolte M. (2016). Goat Care Information, Health and Husbandry and assorted other Tibits.

[47] Nwafor, C. U. (2004). Small ruminant livestock marketing in The Gambia. A socio-economic perspective. Livestock Research for Rural Development. Retrieved on 24-3- 2010 from

http.//www.cababstractsplus.org/abstracts/Abstract.aspx?AcN $o=20043212660$.

[48] Nyendwa, S. (2002). "Go for Goats!" African Farming and Food Processing Article September-October, 15, Nairobi.

[49] Ogola, T. D. O. Nguyo, W. K. and Kosgey, I. S. (2010). Economic contribution and viability of dairy goats.
Implications for a breeding program. Tropical Animal Health and Production, 42, 875-885.

[50] Ojango, J. M., Panandam, J. M., Bhuiyan, A. K. F. H., Khan, M. S., Kahi, A. K., Imbayarwo-Chikosi, V. E., Halimani, T. E., Kosgey, I. S. and Okeyo, A. M. (2010). Higher education. In. Animal breeding in developing countries - Challenges and opportunities. In. Proceedings $9^{\text {th }}$ World Congress on Genetics Applied to Livestock Production. Ed. German Society for Animal Science, Leipzig, Germany, 1-6 August 2010.

[51] Okunlola O. (2000). Constraints and Prospects of goat production.

[52] Oliver S. P, Jayarao B. M and Almeida R. A. (2005). Foodborne pathogens in milk and the dairy farm environment. Food safety and public health implications. Foodborne Pathog Dis 2005; 2.115-129. Tennesse, USA.

[53] Omore, A. O. S. M., Cheng'ole M., Fakhrul I., G. Nurah M., Khan I., and Staal J. S. (2004). "Employment generation through small-scale dairy marketing and processing. experiences from Kenya, Bangladesh and Ghana. A joint study by the ILRI Market-oriented Smallholder Dairy Project and the FAO Animal Production and Health Division". In. Rome FAO.http.//www.fao.org/docrep/007/y4860e00.htm.

[54] Otieno P. E., Muthoni J. W. and Chemining'wa G. N. (2009). Effect of Rhizobia Inoculation, Farm Yard Manure and Nitrogen Fertilizer on Nodulation and Yield of Food Grain Legumes. Journal of Biological Sciences 9(4).

[55] Panin A. (1993). Profitability and income contribution of small ruminant production to rural African household study of Kgatleng and Kweneng districts in Botswana. FAO Corporate document repository. ILRI. Small Ruminants' research and development in Africa.

[56] Peacock, C. and Sherman, D. M. (2010). Sustainable goat production: Some global perspectives. Small Ruminant Research, 89, 70-80.

[57] Peacock, C., (2008). Dairy goat development in East Africa. A replication model for smallholders. Small Rumi. Res 77.225.23.

[58] Rogers, E. M. (2003). Diffusion of innovations (5th Ed.). Free Press, New York.

[59] Salem, B. H. and Smith, T. (2008). Feeding strategies to increase small ruminant production in dry environments. Small Ruminant Research, 77, 174-194.

[60] Shirima E. J. M. (2005). Benefits from dual purpose goats for crop and livestock production under small-scale peasant systems in Kondoa eroded areas, Tanzania. Livestock Research for Rural Development. Volume 17, Article \#138. Retrieved on 11-1-2012, from http.//www.lrrd.org/lrrd17/12/shir17138.htm.

[61] Simm G., Bünger L., Villanueva B. and Hill W. G. (2004). Limits to yield of farm species. Genetic improvement of livestock. In Yields of farmed species. constraints and opportunities in the 21st century (eds Sylvester-Bradley R., Wiseman J., editors.), Nottingham University Press. Nottingham, UK.

[62] Singh R. H. (2011). Perspectives in innovation in the AYUSH sector. Journal of Ayurveda and Integrative Medicine. 2015; 6(3).211-212. doi. 10.4103/0975-9476.166388. Hindu University, Varanasi, India. 
[63] Stone T. (2013). Dairy goats keeping in the humid tropics. $A$ case study of small scale farming systems. Zanzibar.

[64] Tsourgiannis, L., Edison J. and Warren M. (2008). "Factors Affecting the Marketing Channel Choice of Sheep and Goat Farmers in the Region of East Macedonia in Greece. Regarding the Distribution of Their Milk Production". Small Ruminant Research. Canada and Centre for Agribusiness Policy studies, Arizona State University.
[65] Vijay, P. S., Kalpesh, K. and Raj, V. (2009). Determinants of small scale farmer inclusion in emerging modern agri-food markets. A study of the dairy industry in India. Indian Institute of Mangement Ahmedabad India, Working Paper.

[66] Wandera, F. P., Okwach, E. W and Njarui, D. M. G., (2000). Dairy goat research and production in Kenya 20 years on which way; proceedings of a review workshop on small ruminant research programme. KARI, Kenya. 